\title{
Idiopathic spontaneous haemoperitoneum in pregnancy
}

\author{
Mazrin Nur M. A. ${ }^{1 *}$, Rohana I. $^{1}$, Hamidah H. ${ }^{1}$, Syauki H. ${ }^{2}$, Roziana R. ${ }^{1}$
}

\begin{abstract}
${ }^{1}$ Department of Obstetrics and Gynecology, ${ }^{2}$ Department of Surgery, Hospital Sultanah Nur Zahirah, Kuala
\end{abstract} Terengganu, Malaysia

Received: 13 July 2017

Revised: 25 July 2017

Accepted: 08 August 2017

\section{*Correspondence:}

Dr. Mazrin Nur M. A.,

E-mail: drmazrin@gmail.com

Copyright: (c) the author(s), publisher and licensee Medip Academy. This is an open-access article distributed under the terms of the Creative Commons Attribution Non-Commercial License, which permits unrestricted non-commercial use, distribution, and reproduction in any medium, provided the original work is properly cited.

\section{ABSTRACT}

We report a case of a 43-year-old grandmultipara at 26 weeks pregnancy with acute abdomen and in hypovolaemic shock. Urgent exploratory laparotomy revealed massive haemoperitoneum of 9 litres but the exact source of bleeding is obscured despite careful examination of the abdominal organs and vasculature. The patient recovered well post operation but the baby died in-utero.

Keywords: Haemoperitoneum, Idiopathic, Pregnancy, Spontaneous

\section{INTRODUCTION}

Idiopathic spontaneous haemoperitoneum in pregnancy or traditionally known as abdominal apoplexy is a rare event. Although rare, it is important as it is associated with high morbidity and mortality especially when related to pregnancy. Since 1931 the term "abdominal apoplexy" was used to describe a few cases of intraperitoneal hemorrhage secondary to the idiopathic rupture of gastrointestinal arteries. ${ }^{1}$

The term refined to encompass non-traumatic, spontaneous hemorrhage due to rupture of one smaller arteries or veins, and the definition excludes hemorrhage from aortic aneurysm or dissection, gynecological lesions, ectopic pregnancy and visceral malignancy. The presentation of this condition varies widely. Clinical diagnosis is difficult because the symptoms are mostly non-specific. Majority of cases are diagnosed intraoperatively or at postmortem. ${ }^{1}$ It is a real lifethreatening event and immediate management should be made in order to save the patient's life.
We present a case of massive idiopathic spontaneous haemoperitoneum at 26 weeks of pregnancy which resulted in foetal death. To the author's best knowledge, this is the first case of idiopathic spontaneous hemoperitoneum in pregnancy that we are reporting, with a massive intraperitoneal hemorrhage of 9 litres.

\section{CASE REPORT}

Madam NW was a 43-year-old, G6P5 at 26 weeks with underlying Chronic Hypertension. She presented to the Emergency Department with sudden onset of abdominal pain which woke her up from sleep at $4 \mathrm{am}$. Clinically there was mild pallor and her vital signs were stable. The abdomen was tender at the epigastrium and right hypochondriac region with voluntary guarding. Ultrasound assessment demonstrated a live foetus with corresponding parameters, normal liquor volume and normal placenta. Kidneys, liver and gallbladder were all normal. Diagnosis of perforated appendicitis and acute gastritis was made and surgical consultation was sought for. 
In ward, she complained of increased severity of abdominal pain with features of hypovolaemic shock. Clinically she was pale with BP of $80 / 40 \mathrm{mmHg}$ and pulse rate of $106 \mathrm{bpm}$. Free fluid was observed in the Morisson's pouch by a repeat ultrasound. Diagnosis was revised to acute abdomen secondary to ruptured uterus. She was resuscitated with rapid IV fluid infusion and blood, and prompt surgical intervention.

Intraoperatively, there was hemoperitoneum of 9 litres (including 2 litres of blood clots). Uterus was normal with no evidence of uterine rupture. Ovaries, fallopian tubes and utero-ovarian vessels were all normal. Careful and thorough examination of the visceral arteries, veins and solid organs by surgical team were also normal. Postoperative diagnosis was Idiopathic Spontaneous Hemoperitoneum in Pregnancy.

She received 6 units of blood and 2 DIVC cycles. Post operatively in ward, no foetal heart was detected and ultrasound confirmed intrauterine foetal death (IUD). After such a traumatic event, the patient agreed for conservative management for IUD. She was discharged after 7 days post op and was readmitted few weeks later for induction of labour.

\section{DISCUSSION}

More than a century ago, Dr Maurice Barber from Bristol described what is termed today as Idiopathic Spontaneous Haemoperitoneum in Pregnancy in his classic paper published by The British Medical Journal. ${ }^{2}$ Since then many cases were reported worldwide. Earlier papers used the terminology of abdominal apoplexy as suggested by Green and Powers in $1931 .^{3}$ ISIH is the short form of 'Idiopathic Spontaneous Intraperitoneal Haemorrhage' which is a broader terminology encompassing nonpregnant cases while SHIP or 'Spontaneous Haemoperitoneum in Pregnancy' is the diagnosis used in obstetric patients.

Regardless of terminology used, this diagnosis simply describes a condition whereby significant bleeding occurs in the abdominal cavity without any apparent cause. In some cases, the exact source of bleeding is found but in some other cases the source of bleeding remained elusive. Bloody operative field, decreased intra-vascular pressure, and small size of the involved vessel could be among the factors involved in such cases. ${ }^{4}$

To the best of our knowledge no previous case reported as much bleeding as in this case ( 9 litres) whereby the bleeding point was obscured. SHiP jeopardizes the life of both mother and foetus. Published series report maternal mortality ranging from 3.6\%-49\%.5 Maternal mortality associated with SHiP dropped dramatically throughout the years to approximately $4 \% .^{3,6-8}$ Foetal mortality on the other hand remains high involving more than $1 / 3^{\text {rd }}$ of all cases with most deaths attributable to maternal shock. . $^{3,6-8}$ The patient was fortunate to have survived such an ordeal but unfortunately the baby died in utero due to severe asphyxia following massive blood loss.

This patient was in the late $2^{\text {nd }}$ trimester and this is consistent with the findings by Brosen et al. when they reported that typically, women presenting with SHIP are mostly in the second half of pregnancy. ${ }^{9}$ Some cases were also reported during intrapartum and in the early postpartum period. ${ }^{6-8,10}$.

This patient has chronic hypertension which may have contributed to the problem. Green and Powers described 3 out of their 5 patients were hypertensive with atherosclerosis. ${ }^{3} 60 \%$ out of all patients analyzed by Berk et al. ${ }^{10}$ were also hypertensive arteriosclerotic individuals. The exact mechanism is unknown but likely represents weakness of the tunica media, predisposing to rupture in the face of abrupt increases in pressure. ${ }^{11}$ Interestingly in most cases with no identifiable source of haemoperitoneum, essential hypertension and arteriosclerosis were also thought to be responsible..$^{4,6,12}$

Endometriosis is another factor which has been implicated in some cases of spontaneous haemoperitoneum during pregnancy. Brosen et al quoted more than $50 \%$ of cases of SHiP is associated with endometriosis in. ${ }^{8}$ Haemoperitoneum in pregnant women with endometriosis can be caused by spontaneous rupture of utero-ovarian vessels or bleeding endometriosis implants. ${ }^{8}$ In his recent paper, Brosen et al even examined the link between endometriosis, assisted conception and SHiP and concluded that In vitro fertilization in women with severe endometriosis may be a significant risk factor for SHiP. ${ }^{9}$ This patient did not demonstrate any evidence of endometriosis at operation. It is interesting to note that in his earlier paper Brosen et al noticed that in almost half of the affected women, diagnosis of endometriosis was previously unknown until pelvic inspection and biopsy. ${ }^{8}$

Spontaneous haemoperitoneum in pregnancy is a rare event. We hope by reporting this case, we could increase awareness amongst the clinicians regarding this diagnosis.

\section{Funding: No funding sources \\ Conflict of interest: None declared \\ Ethical approval: Not required}

\section{REFERENCES}

1. Smith A, Le D, Guileyardo J, Casanova M. Abdominal apoplexy resulting in small bowel obstruction. Proc (Bayl Univ Med Cent). 2016;29(4):404-6.

2. Barber MC. Intra-abdominal haemorrhage associated with labour. BMJ. 1909;2:203-4.

3. Green WT, Powers JH. Intra-abdominal apoplexy. Ann Surg. 1931;93(5):1070-4.

4. Carr SR, Dinsmore RC, Wilkinson NW. Idiopathic spontaneous intraperitoneal hemorrhage: a clinical 
update on abdominal apoplexy in the year 2001. Am Surg. 2001;67(4):374-6.

5. Katorza E, Soriano D, Stockheim D, et al. Severe intraabdominal bleeding caused by endometriotic lesions during the third trimester of pregnancy. Am J Obstet Gynecol. 2007;197(5):501.e1-e4.

6. Hassani KI, Bounekar A, Gruss JM. Spontaneous rupture of the right gastroepiploic artery: unusual cause of acute abdomen and shock. World J Emerg Surg. 2009;4:24.

7. Passos F, Calhaz-Jorge C, Gra ca LM. Endometriosis is a possible risk factor for spontaneous hemoperitoneum in the third trimester of pregnancy. Fertil Steril. 2008;89(1):251-2.

8. Brosens IA, Fusi L, Brosens JJ. Endometriosis is a risk factor for spontaneous hemoperitoneum during pregnancy. Fertil Steril. 2009;92(4):1243-5.

9. Brosens IA, Lier MC, Mijatovic V, Habiba M, Benagiano G. Severe spontaneous hemoperitoneum in pregnancy may be linked to in vitro fertilization in patients with endometriosis: a systematic review. Fertil Steril. 2016;106(3):692-703.

10. Berk JE, Rothschild NS, Doane JC. Intraabdominal Apoplexy. Ann Surg. 1941;13(4):513-20.

11. Harbour LN, Koch MS, Louis TH, Fulmer JM, Guileyardo JM. Abdominal apoplexy: two unusual cases of hemoperitoneum. Proc (Bayl Univ Med Cent). 2012;25(1):16-9.

12. Cawyer JC, Stone CK. Abdominal apoplexy: a case report and review. J Emerg Med. 2011;40(3):e49e52.

Cite this article as: Mazrin Nur MA, Rohana I, Hamidah H, Syauki H, Roziana R. Idiopathic spontaneous haemoperitoneum in pregnancy. Int $\mathbf{J}$ Reprod Contracept Obstet Gynecol 2017;6:4120-2. 